\title{
LA RESPONSABILIDAD DEL PRODUCTOR POR GARANTÍAS DE BIENES Y SERVICIOS EN EL DERECHO COLOMBIANO*
}

\author{
Juan Carlos Villalba Cuéllar**
}

Fecha de recibido: 2 de febrero de 2013

Fecha de aprobado: 19 de marzo de 2013

Artículo resultado de investigación

Forma de citación: Villalba, J. C. (2013). La responsabilidad del productor por garantías de bienes y servicios en el derecho colombiano. Revista Prolegómenos. Derechos y Valores, 16, 31, 45-67.

\section{Resumen}

La responsabilidad del productor por la garantía de calidad e idoneidad de los productos se rige hoy en día como una subespecie de responsabilidad en materia de protección al consumidor que tiene unos matices especiales. El presente escrito aborda teóricamente la responsabilidad del productor por garantías de bienes y servicios con el fin de delimitar sus características y alcances, y además diferenciarla de algunas figuras tradicionales del derecho privado, tales como la obligación de saneamiento por vicios ocultos y la garantía de buen funcionamiento del Código de Comercio colombiano.

\section{Palabras claves}

Garantía, Responsabilidad del productor, Consumidor, Calidad, Idoneidad.

\section{THE PRODUCER LIABILITY FOR THE GUARANTEE OF GOODS AND SERVICES ON COLOMBIAN LAW}

\begin{abstract}
The producer liability for the guarantee of quality and suitability of products is ruled today as a subspecies of responsibility in regards to consumer protection that has special nuances. This article aims to address theoretically the producer liability for guarantees of goods and
\end{abstract}

Este artículo pertenece a la investigación denominada "La responsabilidad del productor en Colombia", correspondiente al grupo de "Derecho Privado", línea de investigación sobre "Derecho Económico y de los Negocios" que se adelanta en el Centro de Investigaciones Jurídicas, Políticas y Sociales de la Facultad de Derecho de la Universidad Militar Nueva Granada.

* Abogado, docente e investigador, miembro de la línea en Derecho Económico y de los Negocios, grupo en Derecho Privado del Centro de Investigaciones de la Facultad de Derecho de la Universidad Militar Nueva Granada. Magíster LLM en Derecho francés, europeo e internacional de negocios de la Universidad Panthéon-Assas Paris II y el Instituto de Derecho Comparado de Paris (Francia). Especialista en docencia universitaria. Correo electrónico: juan.villalba@unimilitar.edu.co 
services in order to define its characteristics and scope and to differentiate it from traditional private law figures, such as the obligation to repair concealed imperfections and the proper functioning guarantee of the Colombian Commercial Code.

\title{
Keywords
}

Guarantee, Producer Liability, Consumer, Quality, Suitability

\section{A RESPONSABILIDADE DO PRODUTOR NA GARANTIA DE BENS E SERVIÇOS NO DIREITO COLOMBIANO}

\begin{abstract}
Resumo
A responsabilidade do produtor pela garantia de qualidade e adequação dos produtos é governada hoje como uma subespécie de responsabilidade para a defesa do consumidor e que tem nuances especiais. Este artigo tem como objetivo abordar teoricamente a responsabilidade do produtor pelas garantias de bens e serviços, a fim de definir as suas características e realizações, e também distingui-lo de algumas figuras tradicionais do direito privado, tais como a obrigação de saneamento por vícios ocultos e a garantia do bom funcionamento do Código Comercial da Colômbia.
\end{abstract}

\section{Palavras-chave}

Garantia, Responsabilidade do produtor, Consumidor, Qualidade, Adequação.

\section{INTRODUCCIÓN}

En el marco de las relaciones económicas entre productores y consumidores existe un régimen especial de responsabilidad a cargo de los productores y/o proveedores consistente en la obligación de responder por la calidad, idoneidad y seguridad de los productos o servicios que se venden en el mercado. En Colombia la reglamentación de este tema data de 1982 con la expedición del Decreto 3466 de ese año, denominado "Estatuto de Protección al Consumidor", y más recientemente con la expedición de la Ley 1480 de 2011 que actualizó el régimen general de la protección al consumidor en Colombia. Este régimen de responsabilidad adquiere unos matices que lo diferencian de la obligación del saneamiento por vicios contemplada en el Código Civil y de aquel de la garantía a cargo de los comerciantes contemplada en el Código de Comercio. Se trata de un aspecto de gran importancia práctica, ya que miles de contratos de consumo que se celebran día a día quedan cobijados por esta normatividad y además son numerosas las quejas que sobre la materia llegan a la Superintendencia de Industria y Comercio, entidad competente para conocer del mismo. No obstante su relevancia práctica, el tema ha sido descuidado por la doctrina nacional y la carencia de estudios sobre el mismo es palpable: Esto se evidencia además en la reglamentación reciente del tema a través del decreto 0735 de abril de 2013.

Este artículo de reflexión pretende hacer un aporte para llenar ese vacío doctrinal, para lo cual se abordará el tema de la garantía desde el plano teórico, habida cuenta que no existen antecedentes del mismo. El método utilizado será hermenéutico-analítico, a partir del análisis normativo de la garantía en el derecho colombia- 
no, con herramientas de método comparativo e histórico. Para tal fin se examinará primero el concepto de garantía para identificar sus características, así como se estudiarán los casos en que se aplica, las clases de garantías y todos los aspectos que incorpora esta figura, con el objetivo de delimitar bien su naturaleza jurídica y campo de aplicabilidad. En segundo lugar se hará un comparativo de la garantía del derecho del consumo con otras figuras del derecho privado como la responsabilidad por productos defectuosos, los vicios ocultos y la garantía de buen funcionamiento del Código de Comercio.

\section{LA GARANTÍA DE BIENES Y SERVICIOS, DELIMITACIÓN CONCEPTUAL}

\subsection{El concepto de garantía}

El Decreto 3466 de 1982 no definió específicamente la garantía, aunque el tema fue regulado por varios de sus artículos. La mentada norma estableció un sistema de registro público de calidad e idoneidad de los bienes, de carácter voluntario, para que todo productor o importador registrara las características de calidad e idoneidad de los bienes que comercializaba (artículo 3 y 4). No obstante se facultó a la Superintendencia de Industria y Comercio para que en algunos casos estableciera los requisitos mínimos de calidad e idoneidad de los bienes de acuerdo a su naturaleza. Lo anterior sin perjuicio de la existencia de reglamentos técnicos o licencias de fabricación existentes, caso en los cuales la calidad mínima estaba dada por las condiciones establecidas para el bien correspondiente por el respectivo reglamento. La Circular Única de la Superintendencia de Industria y Comercio tampoco definió la garantía. En la escasa doctrina existente en la materia tampoco se encuentran definiciones de la obligación de garantía.

La Ley 1480 de 2011 incluyó un concepto de garantía por primera vez en el ámbito jurídico colombiano, de la siguiente manera: "Obliga- ción temporal, solidaria a cargo del productor y el proveedor, de responder por el buen estado del producto y la conformidad del mismo con las condiciones de idoneidad, calidad y seguridad legalmente exigibles o las ofrecidas. La garantía legal no tendrá contraprestación adicional al precio del producto".

En el contexto comunitario europeo encontramos que la Directiva 1999/44 define la garantía como: "todo compromiso asumido por un vendedor o un productor respecto del consumidor, sin coste suplementario, de reembolsar el precio pagado por un bien de consumo, de sustituirlo, de repararlo o de ocuparse del modo que fuere del bien en caso de que no corresponda a las condiciones enunciadas en la declaración de garantía o en la publicidad correspondiente".

Para Stiglitz y Bru el régimen de garantías legales tiene la finalidad de establecer un marco mínimo e indisponible, de protección en materia de vicios o defectos de los productos o servicios, dentro de los cuales su introducción en el mercado asumen la reparación de los perjuicios ocasionados por la vulneración de los estándares mínimos de identidad y calidad que les son exigibles (2009, p. 401). La finalidad del régimen de garantías en materia de protección al consumidor, en los términos en que está plasmada en la Ley colombiana, consiste en garantizar la conformidad de los productos que se ofrecen en el mercado, más que crear un régimen de reparación de daños ocasionados al consumidor.

En ese sentido parece que su intención primaria y esencial es de carácter compensatorio, cuestión que resulta desafortunada; aunque, tal y como lo explicaremos adelante, en caso de que el consumidor sufra perjuicios tiene alternativas legales para hacer valer la garantía de conformidad y para pedir que le reparen los perjuicios causados. Así las cosas la garantía del derecho del consumo, en principio, tiene por finalidad obtener el cumplimiento forzoso de la obligación, para que se cumpla en los 
términos pactados en el contrato o por equivalencia, y eventualmente da lugar a la resolución del contrato, sin que la Ley 1480 de 2011 expresara la posibilidad de pedir indemnización de perjuicios, contrario a lo que disponía el Decreto 3466 de 1982.

De la definición legal colombiana se pueden extraer varias características de la garantía:

1) Recae en cabeza del productor $y / o$ proveedor: Dentro de la relación de consumo es el productor $y /$ o proveedor, en los términos establecidos por la Ley 1480 de 2011, quien o quienes deben responder por la calidad e idoneidad del bien o servicio que se ofrece en el mercado. Según la legislación nacional todo bien nuevo debe tener garantía, legal o convencional, y responden por ella tanto el productor como el proveedor del bien o servicio, para tal fin la misma norma estableció quiénes tienen la calidad de productor y proveedor en el mercado. Podríamos preguntarnos si algún miembro de la cadena de valor deja de tener esa calidad y podría quedar exonerado de responsabilidad, por ejemplo el transportador, si la mercancía sufre deterioro que afecta su correcto funcionamiento en el transporte. En este caso el consumidor queda protegido pues el transportador es contratado por el importador, fabricante, vendedor o distribuidor y por lo tanto el daño cometido por el transportador le es imputable a quien lo contrató y no podría el mismo exonerarse de responsabilidad alegando culpa de un tercero.

2) Es una obligación temporal: La obligación de garantía se hace exigible una vez se ha establecido una relación de consumo contractual, y a partir de ese momento comienza a correr el término legal o convencional de garantía que constituye un plazo extintivo. Pero esta obligación no es indefinida en el tiempo, la misma se agota cuando se cumpla el término establecido por las partes o por la Ley.
3) Es una obligación solidaria: La obligación de garantía la tienen el productor y/o proveedor solidariamente, entendiéndose así que todos los miembros de la cadena de valor debe responder "in solidum" por la calidad e idoneidad del bien adquirido por el consumidor. El Decreto 3466 de 1982 así lo estableció, aunque creó un régimen diferenciado, la obligación por la garantía mínima presunta recaía directamente sobre el proveedor, según lo dispuesto en el artículo 11, mientras que la obligación por garantías convencionales o diferentes a la mínima presunta estaba en cabeza de productor y/o proveedor en los términos del artículo 12 . A su turno, el artículo 23 del mencionado Decreto establecía que si se trataba de bienes o servicios cuya calidad $e$ idoneidad había sido registrada o respecto al cual existía reglamento técnico, debía responder el productor directamente. En tratándose de bienes importados eran solidariamente responsables el importador y el productor del bien.

La Corte Constitucional y la Corte Suprema de Justicia se pronunciaron en algunas sentencias sobre el carácter de esta responsabilidad. Así, la Corte Suprema de Justicia en sentencia de del 7 de febrero de 2007 afirmó que esa solidaridad tiene origen en el artículo 78 de la Constitución Política cuando establece que "Será responsables, de acuerdo con la Ley, quienes en la producción y comercialización de bines y servicios, atenten contra la salud, la seguridad y el adecuado aprovisionamiento a consumidores y usuarios". Por su parte la Corte Constitucional tuvo la oportunidad de manifestarse sobre la responsabilidad del productor, quien a pesar de no ser contratante se ve obligado, en la sentencia C-1141 de 2000 dijo: "La eliminación legal del productor como sujeto pasivo de las acciones de garantía conectadas con la pretensión de que los bienes y servicios se sujeten a unos parámetros mínimos de calidad, no podría ser objetada si 
no obstante su pretermisión se conservase en esta materia un margen razonable de protección para el consumidor o usuario. Sin embargo, esto no es posible en absoluto. Las condiciones de calidad e idoneidad son las que establece el propio productor o son las que obligatoriamente se imponen a éste. El control del proceso de producción $y$ el diseño del bien o del servicio, incumben de manera directa al productor profesional. El productor obtiene su ganancia por su papel en el proceso de producción $y$, como contrapartida, asume los riesgos derivados de la misma.

En definitiva, suprimir al productor como sujeto pasivo de las acciones de garantía equivale a anular las garantías concedidas o presupuestas, sean éstas de orden legal o convencional. La regulación procesal que produzca este efecto, en lugar de promover la realización del derecho sustancial, lo aniquila. Se puede afirmar, sin vacilación, que en lo que atañe a la conformación de los elementos reactivos del derecho del consumidor, el papel del legislador -por ende el campo de su libertad configurativano consiste en eliminar la responsabilidad del productor en razón de la calidad de sus productos o servicios, sino en determinar los procedimientos más idóneos para hacerla efectiva".

Igualmente añadió: "la supresión del productor como sujeto pasivo de las referidas acciones, equivale a una inmunización contra todo tipo de responsabilidad, lo que contraviene de manera flagrante el texto del artículo 78 de la Carta" (...) supeditar a la voluntad de los expendedores o proveedores de la cadena de comercialización del bien o servicio, la intervención del productor en el proceso, desconoce el papel que debe jugar por sí sólo el consumidor, justamente gracias al régimen de protección legal que debe homologarlo como sujeto titular de la plenitud de sus derechos frente al productor y demás actores económicos, sin necesidad de recurrir a ningún género de mediatización. (...)". Si el agravio lo sufre directamente el consumidor y su causa se radica en la esfera del productor, no se entiende por qué debe ordenarse la reclamación siguiendo la misma secuencia de las transacciones entre las partes inmediatas, cuando la fuente de la responsabilidad la ofrece directamente la Constitución y se sujeta a la realidad objetiva del mercado. (...)".

Posteriormente la Corte Constitucional ratificó estos argumentos en sentencia C -973 de 2002. La Ley 1480 de 2011 desde la definición misma de garantía fue clara en establecer este régimen de solidaridad, reiterado en los artículos 6 y 7 de la norma. Nótese que esta norma es mucho más clara al respecto que el Decreto que la antecedió, ya que establece la solidaridad de productor $\mathrm{y} / \mathrm{o}$ proveedor sin hacer las pluralidad de distinciones del Decreto 3466 de 1982, que algunas veces hacía recaer esta obligación en ambos y otras establecía responsabilidad directa del proveedor. Las imprecisiones del mencionado Decreto fueron aclaradas posteriormente por la SIC y la jurisprudencia estableciendo un régimen solidario de los miembros de la cadena de valor. El texto de la Ley 1480 de 2011 corrobora esas posiciones y no deja hoy ninguna duda, son solidariamente responsables productor $y / o$ proveedor, por lo cual podemos afirmar que importador, distribuidor y vendedor serán solidariamente responsables acogiendo el alcance de las definiciones de productor y proveedor del artículo 5 de la misma Ley. No obstante, esa solidaridad se rompe en el caso de la venta de bienes usados cuya garantía legal haya expirado, pues allí solamente es responsable el proveedor del bien.

4) Está ligada a las condiciones de calidad, idoneidad y seguridad de un bien o servicio. Además su cobertura va más allá e impone obligaciones genéricas a productores y 
proveedores con el fin de garantizar a los consumidores el uso y disfrute del producto. Estas tres palabras son claves cuando se habla de responsabilidad por garantía: calidad, idoneidad y seguridad. En líneas posteriores explicaremos el contenido de cada una de ellas.

5) Se aplica tanto a bienes como a servicios. La Ley 1480 de 2011 y la norma antecesora contemplaron la posibilidad de que la garantía por calidad e idoneidad se aplique tanto en la venta de bienes como en la prestación de servicios. La definición de "producto" en la Ley 1480 de 2011 incluye bienes y servicios.

6) Aplica en contratos a título gratuito u oneroso, ya que la Ley no hizo la distinción es viable hablar de la obligación de garantía en relaciones de consumo a título gratuito. Además porque la definición de proveedor o expendedor de la misma Ley incluye a las personas que prestan servicios $u$ ofrecen productos con o sin ánimo de lucro, allí se configura también relación de consumo. Por ejemplo, si una empresa dentro de sus actividades de responsabilidad social ofrece bienes a personas desfavorecidas responde por la calidad, idoneidad y seguridad de los bienes ofrecidos. Igualmente las entidades sin ánimo de lucro responden por la calidad e idoneidad de sus servicios.

7) Es una especie de responsabilidad especial, no es contractual o extracontractual. Aunque presupone una relación de consumo contractual que la anteceda, son responsables todos los miembros de la cadena de valor sin importar si la relación es contractual o no. Recordemos al respecto que consumidor es el contratante pero también la persona que usa el bien o lo disfruta. En efecto, el principio de la relatividad de los contratos (res inter alios acta) sufre en materia de garantías una derogación.

$\mathrm{Al}$ respecto la Corte Suprema de Justicia en sentencia del 7 de febrero de 2007 dijo:
Precisamente, al amparo de este principio superior puede afirmarse que la tutela efectiva de los intereses de los consumidores y usuarios, habida cuenta de la posición de inferioridad o debilidad que ordinariamente ocupan en el tráfico mercantil y la asimetría que caracteriza sus relaciones jurídico-económicas con los distribuidores o fabricantes, no puede verse restringida o limitada por el principio de la relatividad de los contratos, cuyo alcance, por cierto, tiende cada vez a ser morigerado por la doctrina jurisprudencial, puesto que, con independencia del vínculo jurídico inmediato que ellos pudieran tener con el sujeto que les enajenó o proveyó un determinado bien o servicio, las medidas tuitivas propias de su condición han de verse extendidas hasta la esfera del productor o fabricante, como quiera que éste es quien ha gestionado, controlado o dirigido el diseño y elaboración del producto, entre otros aspectos, así como ha determinado ponerlo en circulación o introducirlo en el mercado, adquiriendo, por contera, un compromiso en torno de la calidad e idoneidad del mismo, por lo que, desde luego, no puede resultar ajeno o indiferente a sus eventuales defectos o anomalías, ni a los peligros o riesgos que estos pudieran generar, como tampoco a las secuelas de orden patrimonial que llegaren a afectar a su destinatario final -consumidores o usuarios- o a terceros, con lo que queda claramente establecida una "responsabilidad especial" de aquél frente a éstos -ex constitutione-, que los habilita para accionar directamente contra el fabricante en orden a hacer efectivas las garantías a que hubiere lugar o a reclamar el resarcimiento de los daños que les fueran irrogados, sin que tal potestad pueda ser coartada por la simple inexistencia de un vínculo de linaje contractual, pues un entendimiento semejante no acompasaría con las directrices inequívocamente fijadas por la Carta Política, pues, como se sostuvo en el fallo que sujetó la constituciona- 
lidad de los artículos 11 y 29 del Decreto 3466 de 1982 precisamente a la existencia de una acción directa del consumidor frente al fabricante, "el productor profesional produce para el mercado, se beneficia del mercado y debe responder ante el mercado (subrayado fuera de texto original).

8) Es responsabilidad objetiva, de tal forma que el productor o proveedor no pueden exonerarse de responsabilidad alegando simple prudencia y diligencia, se trata de un régimen de culpa presunta y el productor solamente podrá alegar las causales enunciadas en el artículo 16 de la Ley 1480 de 2011. La Corte Constitucional en la sentencia C- 973 de 2002 ratificó este carácter: "La norma consagra cuatro causales: fuerza mayor, el caso fortuito no sobrevenido por su culpa, el uso indebido del bien o servicio por parte del afectado $y$ el hecho de un tercero. Al decir que el fabricante solamente se puede exonerar por esas razones está excluyendo "el haber actuado diligentemente". La responsabilidad no se funda en haber ocasionado un daño a otro por su actuación dolosa o negligente en la elaboración de un producto. Incluso podría demostrar el fabricante que actuó con diligencia, y, en todo caso, no se eximiría de su responsabilidad".

\subsection{Cuándo se aplica la garantía del estatuto de protección al consumidor; la relación de consumo}

Resulta de vital importancia para comprender el ámbito de aplicación de las normas de protección al consumidor, recordar que estas se aplican solamente en presencia de la denominada "relación de consumo". La relación de consumo es un vínculo obligacional entre un productor y un consumidor, el cual puede ser de carácter contractual o extracontractual (Villalba, 2012, p. 110). Las normas sobre la garantía de calidad e idoneidad de la Ley 1480 de 2011 solamente se aplicarán cuando se verifique que en unos de los extremos del vínculo obligacional hay un consumidor y un productor $y / o$ proveedor, en el sentido legal de estos términos.

Por lo tanto, si un productor o proveedor vende un bien nuevo a una persona que no actúa como destinatario final, estando ambos dentro de la esfera de sus actividades comerciales habituales, por ejemplo un comerciante vende maquinaria industrial a otro comerciante, la garantía del bien quedará regulada por la normas del Código de Comercio. En cambio, si un productor o proveedor vende un bien a una persona que lo va a destinar a un uso personal, familiar o doméstico, o dentro de una actividad empresarial, siempre y cuando no esté ligado intrínsecamente a su actividad profesional, la compraventa del bien quedará cobijada por las normas de protección al consumidor.

La Superintendencia de Industria y Comercio insiste por mandato legal en la configuración de la relación de consumo para acceder aplicar el régimen de protección al consumidor (Concepto No. 7035587 de 2007). Sin embargo debe anotarse que no en todos los casos los jueces tiene claro este requisito, por ejemplo, en un caso fallado en año 2009 el Tribunal Superior y la Corte Suprema de Justicia aplicaron las normas de protección al consumidor en un litigio en que no existía relación de consumo, en estricto sentido, esto debido a que quien adquirió el bien era un agricultor con el fin de destinar las semillas a una actividad productiva (Sentencia de casación de febrero 7 de 2007).

Igualmente llama la atención que la Superintendencia de Industria y Comercio en la resolución 17928 de 2003, en un asunto sobre garantías, se declaró competente y protegió a una empresa que recibió unos computadores en leasing operativo manifestando que la empresa era consumidor por ser destinatario final, al respecto dijo esa entidad:

En el caso particular, teniendo en cuenta lo anterior, dentro de la relación de consu- 
mo que nos ocupa, Ifileasing S.A. C.F.C. adquirió los bienes objeto de la queja en el mercado, sin transformarlos ni incorporarlos en proceso productivo alguno, entregándolos a la sociedad reclamante para que aquella los utilizara y disfrutara de los mismos, razón por la cual, la sociedad Multidimensionales S.A., ostenta la calidad de consumidor en los términos establecidos en el Decreto 3466 de 1982.

Lo que resulta cuestionable en este caso es que el contrato de leasing es un contrato eminentemente comercial y si una empresa recibe unos bienes en leasing es para utilizarlos en procesos productivos, ligados a su actividad empresarial. Aquí nos encontramos evidentemente frente a una noción amplia de consumidor aplicada por la SIC.

\section{3. ¿Qué comprende la garantía de un bien o servicio: calidad, idoneidad y seguridad?}

La garantía de un bien o servicio a la cual está obligado el productor y/o proveedor según el artículo 6 de la Ley 1480 de 2011 cobija la calidad, idoneidad y seguridad del bien, además del buen estado y funcionamiento de los productos. La obligación de seguridad que quedaría ligada a la garantía se aplicaría en el escenario en que el bien o servicio que se ofrece en el mercado no cuente con los requisitos de seguridad registrados o esperados, de tal forma que puede poner en riesgo la integridad física o la salud del consumidor, sin haber causado un daño todavía, caso en el cual la circulación de ese bien o el ofrecimiento de ese servicio debe ser controlado desde la normas de garantía.

No obstante, la obligación de seguridad está más ligada con el concepto de responsabilidad por productos defectuosos regulado en la misma Ley, así como con las normas relacionadas con el control anterior de calidad e idoneidad que debe hacerse por parte de las entidades gubernamentales, por lo cual su inclusión en este artículo es desafortunada y revela imprecisión en la redacción. Para reforzar este argumento nótese además que en la Superintendencia de Industria y Comercio se canaliza por vía administrativa el control preventivo de seguridad de bienes y servicios $y$ solamente se deciden por vía jurisdiccional demandas relativas a la calidad e idoneidad de los bienes y servicios.

En cuanto a la obligación de garantizar "el buen estado y funcionamiento" de los productos, enunciada en el artículo 7으 de la Ley 1480 de 2011, esta obligación hace parte de aquella consistente en garantizar la calidad e idoneidad del bien, por ejemplo, si un producto se vende como nuevo no está en "buen estado" entonces no tiene la calidad requerida (condiciones inherentes), y si no funciona o funciona mal tiene un problema de idoneidad. Por lo tanto era innecesario enunciar esas dos obligaciones. Aunque esa noción de "buen estado" también podría llevarnos a afirmar que los vicios meramente estéticos quedan incluidos en la garantía, de lo cual no queda duda.

La Ley 1480 se encargó de definir las expresiones calidad e idoneidad, vitales para entender el tema de la garantía:

En cuanto a la calidad se enuncia que es la "condición en que un producto cumple con las características inherentes y las atribuidas por la información que se suministre sobre él". Esta definición varió sustancialmente con respecto a la incluida en el Decreto 3466 de 1982 el cual se identificaba la calidad con las propiedades, ingredientes o componentes que individualizan al bien o al servicio. Con respecto a la nueva definición debe identificarse que se refiere a dos tipos de características, las inherentes al bien o al servicio, y lo inherente será aquello que de acuerdo a la naturaleza del bien o servicio le pertenezca al mismo, por ejemplo que un vehículo automotor marche o tenga motor. En segundo lugar la norma alude a las características atribuidas por la información que se suministre sobre él, aspecto que es nuevo por- 
que el Decreto 3466 de 1982 no lo incluía, y además muy útil porque permite vincular con la obligación de garantía con la información que el productor o proveedor suministraron al consumidor por cualquier medio, la cual es determinante para formar el consentimiento del consumidor y obtener su aceptación. Por ejemplo, si el vendedor le informó al consumidor que el vehículo automotor tenía un motor de 8 válvulas y luego resulta que no cumple con esa característica, a pesar de funcionar correctamente, existe un problema de garantía. En un escrito anterior habíamos señalado la dificultad que tenía la Superintendencia de Industria y Comercio en vigencia de la anterior norma y la interpretación reforzada del Decreto 3466 que hacía la entidad para poder lograr ese efecto (Villalba, 2012, p. 228).

En lo atinente a la idoneidad o eficiencia dice la misma norma que corresponde a la "aptitud del producto para satisfacer la necesidad o necesidades para las cuales ha sido producido o comercializado." Quiere decir que el productor y/o proveedor tiene a su cargo la obligación de garantizar idoneidad del bien, es decir, que sirva para lo que se dice que sirve o se anunció que serviría, por ejemplo que un vehículo automotor marche correctamente.

Algunas normas de protección al consumidor como la brasilera (artículo 19) comprenden vicios de cantidad, y señala esta norma que estos se presentan cuando el contenido líquido fuera inferior a las indicaciones contenidas en el recipiente, en el envoltorio en el rotulado o en el mensaje publicitario. Este aspecto quedaría comprendido por la Ley 1480 de 2011 en Colombia como un asunto de calidad por el no cumplimiento de la información que se suministre sobre el bien.

Debe identificarse además cuál es el criterio establecido por el legislador para determinar si un bien o servicio cumple con las condiciones de calidad e idoneidad. Al respecto del contenido de la Ley 1480 de 2011 se pueden identificar varios criterios:
- La garantía abarca condiciones de calidad e idoneidad que se adecúen a los criterios impuestos por la misma norma al definir esos dos términos, explicadas en líneas anteriores.

- Se responde por la calidad ofrecida (art. 6 Ley 1480 de 2011 y 1.1 Circular Única), es decir que el productor o proveedor responden por las condiciones que le fueron informadas al consumidor. Para efectos de esta responsabilidad no se puede perder de vista que el artículo 24 del estatuto de protección al consumidor diferencia entre la información a la que están obligados a suministrar el productor y el proveedor, lo cual crea un régimen de responsabilidad diferente por información de cada uno de ellos, a nuestro modo de ver totalmente injustificado porque desprotege al consumidor y va en contravía de lo dicho por las altas cortes colombianas frente a este tipo de responsabilidad.

- Se responde por la calidad impuesta por normas técnicas colombianas oficializadas, al tenor de lo dispuesto por el artículo 1.1. de la Circular Única de la Superintendencia de Industria y Comercio.

- La garantía se refiere además a las condiciones de calidad e idoneidad mínimas señaladas en reglamentos técnicos.

- La garantía comprende las condiciones de calidad e idoneidad ordinarias y habituales del mercado. Al respecto la Ley 1480 cuando establece el derecho que tiene el consumidor a recibir productos de calidad dice: "Recibir el producto de conformidad con las condiciones que establece la garantía legal, las que se ofrezcan y las habituales del mercado" (subrayado fuera de texto). La Circular Única de la Superintendencia de Industria y Comercio además señala que "todo productor o expendedor tiene la obligación de garantizar plenamente las condiciones de calidad $e$ 
idoneidad señaladas en las normas técnicas colombianas oficializadas obligatorias o en los reglamentos técnicos y las ordinarias y habituales del mercado" (subrayado fuera de texto). La redacción de estas normas incluye un criterio adicional, lo "lo habitual del mercado", el cual amplía el margen de cobertura de la garantía, en la medida en que el juzgador puede verificar qué es lo que se acostumbra a garantizar al consumidor en el gremio o sector comercial al cual pertenecen el productor $y / 0$ el proveedor para exigirles que cumplan con dichas prácticas.

En síntesis la garantía del derecho del consumo comprende aspectos ligados a la calidad $e$ idoneidad de bienes y servicios, mientras que el deber de seguridad se controla con otras herramientas legales.

\subsection{La garantía de bienes y la garantía de servicios}

Existe igualmente una bifurcación del tema de las garantías en materia de protección al consumidor, las garantías sobre los bienes y las garantías sobre los servicios. Tanto el Decreto 3466 de 1982, anteriormente, como la Ley 1480 de 2011 en la actualidad, aceptan la aplicación del régimen de garantías en estos dos tipos de relaciones de consumo. La noción de producto contemplada en la Ley 1480 de 2011 las abarca en la medida en que "producto" para esta norma es todo bien o servicio. La garantía sobre bienes se aplica tanto a muebles $e$ inmuebles, mientras que la de servicio cobijará todo contrato de prestación de servicios en que exista una relación de consumo, siempre y cuando no tenga un régimen especial. Resulta ser más común que se exija la garantía sobre un bien adquirido porque este presenta defectos o no funciona adecuadamente, mientras que en materia de prestación de servicios a primera vista no aparece tan obvio que el consumidor tenga derecho a la garantía de calidad $e$ idoneidad en la prestación del mismo. Sin embargo, el consumidor está facultado para exigirlas y cuando se trata de prestaciones de servicios en que se adquiere una obligación de resultado la cuestión se simplifica, por ejemplo, si el prestador de servicios de internet se obliga a prestar el servicio a una velocidad determinada y el consumidor no recibe el servicio a dicha velocidad, nos encontramos frente a un problema de calidad del servicio en que se puede hacer exigible la garantía. Así lo ha venido aplicando la Superintendencia de Industria y Comercio desde la vigencia del Decreto 3466 de 1982.

El aspecto controversial surgió recientemente con la puerta que abrió la Ley 1480 de 2011 para la aplicación del régimen de protección al consumidor, incluido el tema de las garantías, a la prestación de servicios de quienes tienen a cargo obligaciones de medio. Inmediatamente se pensó en las obligaciones de quienes ejercen profesiones liberales, por ejemplo, los médicos, por regla general, y también los abogados. La misma Ley 1480 especificó en el artículo 7: "En la prestación de servicios en el que el prestador tiene una obligación de medio, la garantía está dada, no por el resultado, sino por las condiciones de calidad en la prestación del servicio, según las condiciones establecidas en normas de carácter obligatorio, en las ofrecidas o en las ordinarias y habituales del mercado." La dificultad práctica surge en la medida en que se creó un criterio subjetivo para la evaluación de la calidad e idoneidad en la prestación del servicio. El profesor Tamayo Jaramillo considera desacertada esta inclusión (2012, p. 12).

Igualmente debe señalarse que algunas Leyes de protección al consumidor excluyen de su cobertura las relaciones contractuales de quienes ejercen este tipo de actividades, por ejemplo la Ley chilena (19.496) reza: "No se considerará proveedores las personas que posean un título profesional y ejerzan su actividad en forma independiente." Igualmente la Ley argentina (24.240) en su artículo 2 indica que: "No están comprendidos en esta Ley los servicios de profesionales liberales que requieran para su ejer- 
cicio título universitario y matrícula otorgada por colegios profesionales reconocidos oficialmente o autoridad facultada para ello, pero sí la publicidad que se haga de su ofrecimiento".

Para Fernández la aplicación del régimen de garantías en materia de servicios médicos resulta desfavorable al consumidor como consecuencia de los plazos tan cortos con que cuenta el consumidor para ejercer la acción sumado a la carga probatoria que se le impone al consumidor de probar el defecto del servicio (2013, p. 525).

\subsection{Las clases de garantías y sus términos}

En el Decreto 3466 de 1982 se podían identificar tres clases de garantías, la garantía mínima presunta, la garantía convencional y la garantía obligatoria. La garantía mínima presunta era aquella que se entendía pactada en todos los contratos de compraventa y de prestación de servicios y comprendía la obligación a cargo del productor de garantizar plenamente las condiciones de calidad e idoneidad señaladas en el registro o en la licencia correspondiente (artículo 11). La garantía convencional era aquella otorgada voluntariamente por el productor $y / o$ proveedor diferente la mínima presunta, es decir aquella de manera expresa y por un término determinado se le otorgaba al consumidor. En tercer lugar existía la garantía obligatoria que surgía cuando la Superintendencia de Industria y Comercio imponía términos mínimos obligatorios para ciertos bienes o servicios.

En la Ley 1480 la regulación de las garantías se modifica y las clases de garantías que encontramos son las siguientes: la garantía legal, la garantía suplementaria y la garantía obligatoria.

La garantía legal es aquella que en los términos del artículo $7^{\circ}$ está a cargo de todo productor y/o proveedor, el término de esta puede ser el legal o "convencional", el primero tiene ca- rácter suplementario y entra a regir en caso de que el productor no haya expresado un término de garantía diferente al consumidor.

Los términos de garantía legal están expresados en el artículo 8 de la Ley 1480 de 2011, para bienes nuevos el término es de un año, para bienes perecederos es la fecha de vencimiento, para bienes usados el término es de tres meses, aunque estos pueden ser vendidos sin garantía, siempre y cuando se le advierta expresamente la consumidor; la prestación de servicios que suponen la entrega de un bien para su reparación se puede pactar sin garantía siempre y cuando se le informe al consumidor y este acepte por escrito, en caso de no indicarse tienen término de garantía de tres meses; para los inmuebles el término de garantía por estabilidad de obra es de diez años y para los acabados es de un año. Así las cosas el legislador quiso que en Colombia no se venda ningún bien nuevo sin garantía de calidad, idoneidad y seguridad.

Se señala como novedoso que se incluyan los bienes inmuebles y se fijen unos términos mínimos (Giraldo, Caycedo \& Madriñan, 2012, pp. 53-54). No obstante la novedad es relativa, ya que el Código Civil colombiano en su artículo 2060 estableció desde hace mucho tiempo un régimen de responsabilidad presunta del constructor por vicios de construcción por un término de 10 años, el cual sí es incontrovertible a diferencia del establecido en la Ley 1480. La verdadera novedad consiste en que de ahora en adelante se podrá discutir el tema de la garantía de bienes inmuebles, siempre y cuando haya relación de consumo, a través de procedimientos de protección al consumidor lo que implica la aplicación de la inversión de la carga de la prueba y todos los principios pro consumatore.

El decreto 0735 de 2013 reglamentó los plazos y la forma en que se hace efectiva la garantía de inmuebles nuevos en cuanto a acabados y líneas vitales, así como en lo atinente a la garantía por estabilidad de la estructura. 
La garantía suplementaria es aquella que se ofrece adicionalmente al consumidor, más allá de los términos de la garantía legal, la cual puede ser gratuita $\mathrm{u}$ onerosa. Cuando sea onerosa se deberá obtener el consentimiento expreso del consumidor y dejar constancia escrita de la misma.

La garantía obligatoria sigue existiendo en la medida en que el artículo 59 de la Ley 1480 de 2011 le permite a la Superintendencia de Industria y Comercio dentro de sus funciones administrativas establecer el término de garantía de ciertos bienes y además las garantías obligatorias fijadas por la entidad anteriormente siguen vigentes. En la Circular Única de la Superintendencia se fijan términos obligatorios de garantía mínima para vehículos automotores y baterías de vehículos.

Con respecto a la regulación de las garantías en la Ley 1480 de 2011, en escrito anterior se expresó que merece una crítica el carácter subsidiario de los términos de la garantía legal, en la medida en que el productor puede establecer términos inferiores de garantías, lo cual en nuestro sentir es desafortunado para los consumidores. Pensar que los términos de garantía son un asunto que se regula bien desde el juego de la libre competencia es poco garantista de los derechos de los consumidores (Villalba, 2012, p. 230). No obstante esta fue la posición de los redactores de la Ley 1480 de 2011, De la Cruz (2012) asume una posición más liberal y crítica la norma con respecto a la disposición que no permite modificar la responsabilidad por garantía a cargo del productor. Al respecto el autor expresa que el tema de la garantía y su alcance debe ser un factor de competencia en el mercado, motivo por el cual debe dejarse a los consumidores escoger a quien les ofrezca la mejor garantía, siempre y cuando se le informe adecuadamente (pp. 17,18).

Aclara la doctrina que en caso de que el productor fije un término y condiciones de garantía, estas no podrán ser disminuidas o desmejoradas por los expendedores que participan posteriormente en su comercialización, salvo que sea para mejorarlas (Giraldo, Caycedo \& Madriñan, 2012, p. 47). Lo anterior quedó expresamente contemplado en el decreto 0735 de 2013 (artículo 23).

De la anterior clasificación también se puede inferir que la norma de protección al consumidor en materia de garantías amplió la cobertura legal con respecto a la norma anterior, $y$ hoy en día se aplica sin duda alguna la adquisición de bienes muebles e inmuebles, bienes nuevos y bienes usados, de bienes consumibles y no consumibles. Nótese que en legislaciones como la argentina se excluyen los bienes consumibles se este régimen.

\subsection{Aspectos que comprende la garantía de un bien o servicio}

De acuerdo a lo dispuesto en la legislación colombiana en derecho del consumo encontramos que la garantía legal abarca dos grupos de obligaciones a cargo de los productores $\mathrm{y} / \mathrm{o}$ proveedores. El primer grupo de obligaciones consiste en que una vez se presente el defecto o falla del bien o servicio el consumidor está facultado para exigir la garantía del mismo, contenida en los numerales 1, 2, 3, 8 y 9 del artículo 11 de la Ley 1480 de 2011. En el segundo grupo se expresan otro tipo de obligaciones que el productor $\mathrm{y} / \mathrm{o}$ proveedor tienen en todo momento, que hacen parte de la garantía legal, con independencia de que el bien presente desperfectos o no, incluidas en los numerales 4, 5, 6 y 7 del citado artículo. Señala Zentner que Farina hace la crítica a la falta de unidad de este régimen en el derecho argentino, ya que la garantía presupone un cumplimiento irregular a cargo de la prestación del productor o proveedor, y el segundo grupo de obligaciones como la de proveer servicio técnico o repuestos están orientadas a que el consumidor optimice la utilización del bien (2010, p. 252).

Los aspectos incluidos en la garantía legal enumerados en el artículo 11 de la Ley 1480 de 2011 y el decreto 0735 de 2013 son los siguientes: 
- En primer lugar el productor y/o proveedor está obligado a reparar el bien de manera gratuita, si este admite reparación, si no admite reparación se procederá a la reposición del bien o a la devolución del dinero. En este caso el consumidor no puede exigir inmediatamente el cambio del producto o la devolución del dinero porque la primera alternativa es la reparación. Aunque a veces sucederá que el bien no se puede reparar, por ejemplo porque se trata de un defecto de diseño que implicaría rehacerlo o el defecto es tan grave que la reparación se hace inviable. El plazo para la reparación del bien es de 30 días salvo disposición especial en contrario y en el evento que al consumidor se le entregue un bien en préstamo mientras se le repara el bien el plazo se extenderá hasta 60 días (decreto 0735 de 2013, art. 8).

- En caso de repetirse la falla, asumimos que esto pasará cuando el bien es cambiado por otro o en caso de que sea reparado, dependiendo de la naturaleza del bien o las características del defecto, a elección del consumidor se procederá a una nueva reparación, devolución total o parcial del precio o cambio total o parcial del bien por una de la misma especie, similares características o especificaciones técnicas. Con respecto a lo anterior cabe señalar que la norma deja a la potestad del consumidor escoger entre varias opciones, pero al indicar que "dependiendo de la naturaleza del bien o las características del defecto" pareciera dar unos criterios que restringirían en algún momento esa facultad, lo cual no tiene justificación.

Ahora bien, si la falla se repite en algunos casos el consumidor ya no deseará comprar el bien de las misma marca o referencia, y es más, seguramente en algunos casos no querrá volver a tener relaciones comerciales con el productor o vendedor, lo cual justifica la potestad que le da la Ley bajo esas circunstancias. Esta norma deja además sin piso la expresión que esporá- dicamente utilizan algunos comerciantes al afirmar "aquí no se devuelve el dinero", pues se trata de una obligación y no de una alternativa. También puede suceder que cuando se va a cambiar el bien ya no se cuenta con el mismo producto en el almacén o este ha sido descontinuado, caso en el cual se puede cambiar por otro que no sea exactamente el mismo, pero sí equivalente en sus características, siempre y cuando el consumidor acepte, porque de lo contrario este podrá exigir que le devuelvan el dinero, según el artículo $5 \mathrm{del}$ decreto 0735 de 2013. Además el mismo decreto aclara que la suma de dinero a devolver es el valor pagado (precio de venta) por el bien en el momento de la compra $y$ no el valor del bien en el momento de hacerse exigible la garantía (art. 6).

- En cuanto a la garantía de prestación de servicios, ese mismo artículo dice que cuando haya incumplimiento se procederá, a elección del consumidor, a la prestación del servicio en los términos en que fue contratado o a la devolución del dinero.

- Además de estas opciones la Ley 1480 de 2011 va más lejos, pues incluye como obligaciones implícitas en la garantía una obligación de información, consistente en suministrar las instrucciones para la instalación, mantenimiento y utilización de los productos (bienes o servicios). Este aspecto se debe leer concordantemente con las normas sobre el deber de información de la misma Ley, por lo cual podemos adicionar que la información debe ser clara, veraz, suficiente, oportuna, verificable, comprensible, precisa e idónea. Se trata evidentemente de un deber de información contractual.

- Igualmente el artículo 11 impone la obligación de disponer asistencia técnica para la instalación, mantenimiento y utilización de los productos, aunque se puede cobrar por ella. Todo depende del carácter de esa asistencia técnica, por ejemplo, si la misma es 
imprescindible para la instalación, lo que implica que si el consumidor no es asistido queda privado de la posibilidad de usar el bien, esa asistencia se torna obligatoria.

- La garantía también implica la entrega del producto, en este aspecto la Superintendencia de Industria y Comercio en vigencia de la anterior norma consideraba que el hecho de no poder gozar el producto es un asunto relativo a la garantía. Por esa misma razón cuando el proveedor o productor retarda la entrega del bien el consumidor cuenta con las normas sobre garantía para hacer valer sus derechos, inclusive para exigir que le devuelvan el dinero.

- Así mismo la norma obliga al productor o proveedor a contar con la disponibilidad de repuestos, partes, insumos y mano de obra capacitada, incluso después de vencida la garantía, por el término anunciado por la autoridad competente, por el productor $\mathrm{o}$ el que se acostumbre en el mercado.

- Se debe garantizar adicionalmente las partes, insumos o componentes adheridos a los bienes inmuebles que deban ser cambiados por efectividad de la garantía, por otros de igual o mejor calidad, aunque no exactamente los mismos. Esta norma está destinada al consumidor inmobiliario, de vivienda nueva, para prever el caso en que el constructor debe responder por los acabados o por vicios de construcción y al efectuar las reparaciones no cuenta con los mismos materiales, lo cual algunas veces genera desacuerdos entre el propietario del inmueble y el constructor porque afecta o altera la estética anterior del inmueble.

- Finalmente, en los contratos de prestación de servicios que suponen la entrega de un bien, repararlo, sustituirlo o pagar su equivalente en dinero en caso de destrucción total o parcial ocasionada por servicios defectuosos. Este numeral del artículo 11 se refiere a un evento de responsabilidad por servicio defectuoso, cuando el bien entregado para reparación ha sido destruido por el prestador del servicio.

Nótese, para reafirmar lo dicho antes, que los numerales 4 a 7 del artículo 11 de la Ley 1480 de 2011 imponen obligaciones que hacen parte de la garantía pero que no tienen que ver directamente con problemas de calidad e idoneidad del bien, por ejemplo contar con asistencia técnica y suministrar manuales de instrucciones son obligaciones que operan de manera permanente para los productores sin necesidad de que el bien esté presentando fallas. Lo anterior pone de manifiesto que la obligación de garantía en los términos del estatuto de protección al consumidor es muy amplia.

Cuando se trata de contratos de suministro de servicios (como internet, telefonía celular, televisión por cable) el prestador se obliga a prestar el servicios de manera constante y en el caso de que no sea prestado o se preste en condiciones deficientes el consumidor tiene derecho a no pagar el tiempo que recibió el servicio y en caso de que le haya sido cobrado tiene derecho a obtener compensación o devolución de ese cobro indebido (Giraldo, Caycedo \& Madriñan, 2012, p. 53).

Tal y como se señaló al comienzo de este texto la forma en que quedó regulado el tema de la garantía en la Ley colombiana hace pensar en un régimen compensatorio más que indemnizatorio, porque la Superintendencia de Industria y Comercio no tiene la posibilidad de decretar indemnizaciones de perjuicios en materia de garantías, competencia que sí tienen los jueces ordinarios. El Decreto 3466 de 1982 permitía decretarlos, pero con fundamento en una interpretación errada de la Ley 446 de 1998 (artículo 145) por parte de la SIC esta entidad se negó a reconocerlos (Sentencia núm. 54930 de 2010). Posteriormente la redacción de la Ley 1480 de 2011 acabó de perjudicar al consumidor porque nada dice al respecto y se aplica plenamente la Ley 446 de 1998 y por si fuera poco, el decreto 0735 
de 2013 en el artículo 22 expresa que el reconocimiento de la garantía no impide que el consumidor exija la indemnización de perjuicios ante la jurisdicción ordinaria, motivo por lo cual no queda duda al respecto.

$\mathrm{Al}$ respecto, se considera que el hecho de que la Ley 1480 de 2011 no se haya referido a la posibilidad de decretar indemnizaciones de perjuicios derivada de la garantía del derecho del consumo, no implica que esta posibilidad esté descartada, los jueces ordinarios han decretado estas indemnizaciones, tal y como se corrobora en la sentencia de la Corte Suprema de Justicia de febrero 7 de 2007, en un asunto en que se alegaba la calidad de unas semillas. Sin embargo esto no tiene ninguna justificación, actuando ambos como jueces deberían tener las mismas facultades. Resulta incomprensible que la Superintendencia de Industria y Comercio no pueda decretar perjuicios a favor del consumidor derivados del incumplimiento del deber de garantía, cuando el consumidor además de verse privado del bien por la falta de calidad $e$ idoneidad sufre perjuicios por la imposibilidad de disfrutar del mismo. No se entiende cómo la entidad puede ordenar por vía jurisdiccional devolver el dinero, la reparación del bien o el cambio del mismo (resolución o cumplimiento), más no está facultada para ordenar que se indemnicen los perjuicios causados, esto deja a la entidad en sus funciones jurisdiccionales en calidad de un juez que puede actuar "a medias".

No obstante la solución planteada, queda latente el problema de injusticia en los casos de mínimas cuantías en que el consumidor, por falta de conocimiento, acude a la SIC y además de las consecuencias contempladas en la Ley 1480 de 2011, pide que se le indemnicen los perjuicios, porque seguramente no obtendrá la satisfacción de esta última pretensión.

Otra posibilidad que no puede descartarse es que el consumidor opte por ejercer únicamente la acción resolutoria por incumplimiento, conforme a las normas civiles y comerciales, añadiendo eventualmente la solicitud de indem- nización de perjuicios. Con respecto a esta posibilidad, Rinessi (2006) y Mosset Iturraspe (2008) agregan que negarle la posibilidad de resolución al consumidor implicaría contradecir el carácter tuitivo del régimen de garantías establecidas en las Leyes de protección al consumidor. Así las cosas, todas estas posibilidades están vigentes, dependiendo cual sea la solución más favorable al consumidor en cada caso, en aplicación del principio favor consumitoris. La Corte Suprema de Justicia en sentencia de agosto 4 de 2009 al resolver un caso de vicios redhibitorios en sus consideraciones manifestó que el afectado tiene una gama de posibilidades para demandar, entre las cuales consideró la acción derivada de la garantía del bien.

\subsection{Causales de exoneración}

Como quiera que se trata de una especie de responsabilidad objetiva, las causales de exoneración del productor $\mathrm{y} / \mathrm{o}$ proveedor tiene un carácter restringido. Según la Ley 1480 de 2011 y su norma antecesora son cuatro las causales de exoneración válidas que pueden esgrimir el productor y/o proveedor en materia de responsabilidad por garantías de bienes:

a) Fuerza mayor o caso fortuito.

b) El hecho de un tercero.

c) El uso indebido del bien por parte del consumidor, $y$

Que el consumidor no atendió las instrucciones de instalación, uso o mantenimiento indicadas en el manual del producto y en la garantía.

Estas cuatro causales de exoneración solamente operarán para las obligaciones contenidas en los numerales 1, 2, 3, 8 y 9 del artículo 11 del estatuto de protección al consumidor.

Ahora bien, resulta curioso que la norma de protección al consumidor colombiana es de las pocas (sino no la única) que incluye causales de exoneración de la obligación de garantía, lo cual resulta discutible. Admitir al productor exonerarse de responsabilidad por un defecto 
de fabricación de un bien porque un evento de fuerza mayor o caso fortuito ocurrido en su planta de producción ocasionó un defecto del bien, que impide su correcto funcionamiento, es totalmente inadmisible. Lo mismo sucedería si el productor alega que no responde porque un tercero ajeno a su planta de producción alteró el funcionamiento normal del proceso de ensamblaje, ese es un asunto ajeno totalmente al consumidor. La carga probatoria de todos modos la tendrán el productor y el proveedor. La norma al permitir esa causal de exoneración entra en contradicción con lo que la Corte Constitucional ha reiterado, al decir que se trata de una responsabilidad de mercado. Aunque debe recordarse que este aspecto fue revisado tangencialmente por la Corte Constitucional en sentencia C- 973 de 2002, porque no fue el motivo de la demanda, y allí el tribunal encontró fundadas las causales de exoneración.

La posición planteada es compartida con Mantilla (2013) considera que permitir la exoneración por causa extraña "no sólo no corresponde a la noción técnica de garantía, sino que, además implica una menor protección para el comprador consumidor, si se compara con lo dispuesto por las garantías de buen funcionamiento y por vicios ocultos".

\section{LA GARANTÍA DE BIENES Y SERVICIOS, DIFERENCIAS CON OTRAS FIGURAS DEL DERECHO PRIVADO}

\subsection{La garantía y su diferencia con los vicios redhibitorios}

El Código Civil incluye como una de las obligaciones del vendedor la obligación de saneamiento o garantía por vicios, y entre esos vicios se refiere a los vicios redhibitorios, ocultos, o de naturaleza intrínseca, de la cosa vendida. Según Bonivento todo comprador al celebrar un contrato persigue una utilidad o provecho de la cosa adquirida: que le sirva para su uso normal (2012, p. 144). Para Tamayo los vicios ocultos son los defectos imperceptibles de la cosa, que a pesar de existir en el momento de la venta, el comprador no pudo ni hubiera podido descubrirlos y que el vendedor no le reveló; defectos que hacen la cosa inapropiada para el uso a que estaba destinada, o sólo le permite un uso deficiente (2004, p. 175).

Cuando el comprador ve disminuida esa facultad de goce, y se altera el equilibrio de las prestaciones, es cuando surge esta obligación de saneamiento, que como dice el artículo 1914 del Código Civil colombiano, confiere la acción redhibitoria, o sea, la que tiene el comprador para que se rescinda la venta o se rebaje proporcionalmente el precio por los vicios ocultos, conocida como acción estimatoria (Bonivento, 2012, p. 144).

Empero, para que un vicio de la cosa vendida se pueda considerar oculto se necesitan ciertos requisitos señalados por el Código Civil:

1) El vicio debe haber existido al tiempo de la venta, es decir el origen del vicio debe ser anterior al perfeccionamiento del contrato de compraventa. Señala al respecto Gómez Estrada que "de un vicio generado con posterioridad al contrato de venta no puede hacerse responsable al vendedor, no solamente porque la misma razón natural lo enseña, sino porque legalmente son de cargo del comprador los riesgos de la cosa a partir del perfeccionamiento del contrato" (2008, p. 101), según el artículo 1876 del Código Civil.

2) El vicio debe ser tal o tales, que por ellos la cosa vendida no sirva para su uso normal, o sólo sirva imperfectamente, de manera que sea de presumir que conociéndolos el comprador no la hubiera comprado o la hubiera comprado a menos precio. Esta clase de vicios facultan para ejercer la acción redhibitoria, mientras que si el vicio no tiene tal importancia el comprador solamente queda facultado para ejercer la acción de rebaja del precio, tal y como lo dispone el artículo 1925 del Código Civil. 
3) No haberlos manifestado el vendedor, y ser tales que le comprador haya podido ignorarlos sin negligencia grave de su parte, o tales que le comprador no haya podido fácilmente conocerlos en razón de su profesión u oficio. Para el profesor Gómez Estrada que los dos anteriores requisitos son objetivos, mientras que este último es de carácter subjetivo (2008, p.102).

En un estudio sobre el tema de los vicios redhibitorios Oviedo señala que:

Los tribunales de Colombia y Chile asumen de forma coincidente que el supuesto fundamental para considerar que el bien está afectado por un vicio, es que este se refiera a defectos físicos que pueden tener origen interno o externo y consistir en: defectos de composición, defectos de construcción $y$ diseño, defectos de insuficiencia material, defectos de elaboración y envase, defectos de salubridad, defectos de descomposición o contaminación, que produzcan el efecto de impedir o reducir el uso natural o pactado del mismo (2010, p. 262).

Ahora bien, la garantía que regulan las Leyes de protección al consumidor se diferencia de los vicios ocultos del Código Civil en varios aspectos. La legislación argentina en materia de protección al consumidor hace la diferencia entre las dos figuras en los artículo 11 a 18 de la Ley 24.240 (Hise, 2012, p. 269). A continuación enunciaremos algunas de las diferencias encontradas entre las figuras en mención:

a) La garantía legal del derecho del consumo tiene una cobertura más amplia, comprende vicios ocultos y vicios no ocultos, en derecho civil es necesario que el vicio exista así sea en germen con anterioridad al momento de perfeccionamiento del contrato, mientras que en derecho del consumo la obligación de garantía tiene vocación a ser aplicada así el bien estuviese en perfecto estado en el momento de la celebración del contrato, por ejemplo, el vehículo que adquiere el con- sumidor funciona bien cuando se celebra el contrato, está en buen estado, pero por la deficiente información que le da el productor, con posterioridad se generan fallas que alteran su buen funcionamiento. Así que en materia de derecho del consumo se atempera la regla del derecho civil que dice que los riesgos de la cosa vendida son a cargo del comprador, por lo menos en cuanto a los riesgos por mal funcionamiento. Lorenzetti señala que las garantías en materia de protección al consumidor exceden el vicio intrínseco para abarcar la expectativa que el adquirente tenía sobre el bien (2009, p. 301).

b) En materia civil se exige que se trate de vicios que el comprador no estaba en capacidad de identificar, es decir que sean ocultos, mientras que en materia de protección al consumidor esta distinción no tiene ninguna relevancia, puede que el consumidor estuviese en capacidad de detectarlos, la norma obliga de todos modos a que los bienes o servicios que se vendan en el mercado tengan garantía, se trata de un imperativo para el productor en el mercado. Al respecto Barocelli indica que en el derecho del consumidor los vicios pueden ser manifiestos (2012, p. 4) apoyado en la legislación argentina que en materia de garantía comprende vicios ostensibles según el artículo 11 de la Ley 24.240. En cuanto a los vicios ostensibles vale la pena preguntarse si aplica la noción de consumidor racional, es decir si debe ser protegido aquel consumidor que actúa torpemente y adquiere por ejemplo un bien visiblemente averiado. En este caso si el consumidor no fue informado no se puede aplicar la noción de consumidor racional porque el régimen de responsabilidad objetiva protege al consumidor y por lo tanto el productor y proveedor deben responde por la garantía legal.

c) La garantía del derecho del consumo no se limita al tema de los vicios porque también se aplica en algunos eventos en que el bien no tiene un vicio, tal y como sucede cuando 
el bien, siendo idóneo, no corresponde al bien ofrecido por el productor $y / o$ proveedor. Ejemplo: el consumidor adquiere por internet un bien y cuando lo recibe en su casa le entregan otro que funciona bien pero no tiene las características del ofrecido. Al respecto debe recordarse que la Ley 1480 de 2011 en el artículo 6, numeral 5 indica que la garantía se liga con las condiciones ofrecidas por el productor o proveedor. Igualmente sucede que si un productor o proveedor incumplen con la entrega del bien dentro del término pactado con el consumidor, por tratarse de una condición ofrecida se aplica la protección en materia de garantía.

d) En materia de vicios ocultos se requiere que el vicio sea grave para poder hacer uso de la acción redhibitoria, esta gravedad implica que el bien no sirva para su uso natural o sirva imperfectamente, pues si no reviste tal gravedad solamente cabe la acción de rebaja del precio. No obstante lo anterior en la legislación y jurisprudencia colombiana se presenta una zona gris en la materia, pues la Corte Suprema de Justicia sentencia de 2005, en la cual cita varias sentencias que la antecedieron, dio a entender que para que procedan las acciones edilicias derivadas del contrato de compraventa el vicio debe ser de menor entidad (Sala de Casación Civil 14 de enero de 2005). En cambio, en materia de garantías de derecho del consumidor el criterio de gravedad no es determinante, basta con que la presencia del vicio afecte el principio de la identidad del pago y que afecte, aunque no impida, el correcto funcionamiento de la cosa (Mosset \& Wajntraub, 2009, p. 129).

e) La consecuencia jurídica es diferente, en el caso de los vicios ocultos el comprador puede optar por la rescisión o la rebaja del precio, mientras que en el caso de garantía el consumidor tiene las siguientes posibilidades, la reparación del bien (si esta es posible), el cambio del bien por otro que se idóneo o que corresponda al ofrecido, o la restitución del dinero, esta última sí correspondería la resolución del contrato.

f) En materia de vicios ocultos se puede acumular la pretensión de indemnización de perjuicios cuando el vendedor conocía los vicios y no los declaró o si estos eran tales que el vendedor haya debido conocerlos por razón de su profesión u oficio según lo preceptuado en el artículo 1918 del Código Civil colombiano. Lo anterior implica que para poder pedir indemnización de perjuicios en materia civil por vicios ocultos se debe demostrar la mala fe del vendedor. Mientras tanto la garantía de bienes en derecho del consumo no permite acumular indemnización de perjuicios cuando la acción se intenta ante la Superintendencia de Industria y Comercio, entidad que no tiene facultad en este tema para decretarlos, mientras que si se intenta la acción ante el juez civil esta pretensión es viable. En el caso de acumular la pretensión de indemnización de perjuicios ante el juez civil el consumidor tendrá una ventaja, la inversión de la carga de la prueba y la presunción de culpa del proveedor $y / 0$ productor.

g) En materia de vicios ocultos del Código Civil quien responde es el vendedor, mientras que en materia de protección al consumidor por garantías deben responder el productor y el proveedor solidariamente según el artículo 10 de la Ley 1480 de 2011.

h) En cuanto a la carga de la prueba en materia de vicios ocultos corresponde al comprador demostrar que el vendedor conocía los vicios y no los declaró o si estos eran tales que el vendedor haya debido conocerlos por razón de su profesión u oficio según lo preceptuado en el artículo 1918 del Código Civil colombiano. En materia de protección al consumidor existe una presunción de culpa del productor o proveedor, de tal forma que el consumidor solamente debe demostrar la relación de 
consumo y el defecto del bien. Tal y como lo dijimos, es irrelevante en materia de protección al consumidor si el productor o proveedor sabían de los defectos del bien o estaban en capacidad de saberlo, legalmente existe una presunción al respecto. El productor solamente podrá exonerarse de responsabilidad alegando las causales enunciadas en la Ley 1480 de 2011.

i) Igualmente los términos de prescripción son diferentes, en materia civil el término para ejercer la acción redhibitoria es de seis meses con respecto a las cosas muebles y de un año con respecto a los bienes raíces, así como para ejercer la acción de rebaja del precio (cuanti minoris) es de un año para bienes muebles y 18 meses para los bienes inmuebles (artículo 1923 y 1925 del Código Civil). El Código de Comercio impone término de seis meses de prescripción de las acciones derivadas de vicios ocultos sin distinción alguna. En tratándose de garantías el término de prescripción de la acción es de un año a partir del momento de expiración del término de la garantía, dependiendo si es legal o convencional.

j) En materia de vicios ocultos el legitimado por activa para demandar es el comprador, en materia de garantía el legitimado para exigir la garantía es el consumidor, quien no necesariamente es el comprador, puede ser el destinatario del bien.

k) En materia procesal también surgen diferencias, en materia de juez competente y tipo de procedimiento a seguir, así, mientras en lo relativo a vicios ocultos es competente el juez civil y el trámite será el procedimiento verbal, en lo atiente a garantías serán competentes el juez civil o la Superintendencia de Industria y Comercio, entidad que tiene facultades jurisdiccionales al respecto, y el procedimiento a seguir es el verbal sumario para mínimas cuantías y el verbal para menor y mayor cuantía, según el Código General del Proceso a partir del año 2014, así como las reglas procesales de la acción de protección al consumidor consagradas en la Ley 1480 de 2011.

Así las cosas, una vez aclarado que se trata de dos figuras diferentes se puede afirmar que, dependiendo el caso, el consumidor está facultado para escoger entre algunas de estas, ya que la obligación de saneamiento por vicios redhibitorios no está encaminada a la reparación del bien o sustitución del bien (Zetner, 2010, p. 253).

Todo depende además de lo pretendido por el consumidor, porque si el defecto es tal que solamente quiere deshacerse el contrato la Ley 1480 no resulta conveniente, porque esta le da la oportunidad al vendedor primero de reparar, segundo de cambiar y tercer del devolver el bien. En caso de que se trate de un defecto posterior a la venta o un problema de información la única acción posible será la de protección al consumidor por efectividad de la garantía.

\subsection{Diferencias de la garantía del derecho del consumo y la garantía de buen funcionamiento del Código de Comercio}

El Código de Comercio colombiano incorporó una obligación de garantía a cargo del comerciante, consistente en una garantía de buen funcionamiento, la cual debe ser pactada expresamente por las partes (artículo 932) y además se entiende pactada cuando se trata de bienes en que se acostumbran vender con garantía (artículo 933). Para Bonivento los artículos 916 y 931 del Código de Comercio contemplan además una especie de garantía general que no tiene relación con el saneamiento por vicios redhibitorios (2012, p. 153). Estas normas a nuestro modo de ver más que una especie de garantía se aproximan la figura de la falta de conformidad.

Adicionalmente el Código de Comercio se refiere a los vicios intrínsecos cuando consagra la obligación del vendedor de responder por los vicios ocultos, con los mismos condiciona- 
mientos que impone el Código Civil. Aquí ya se encuentra un avance de la legislación mercantil con respecto a la civil, consistente en que el Código de Comercio contempló varias hipótesis, que cubren tanto vicios intrínsecos (ocultos) como vicios ostensibles, además de otros eventos como la no conformidad.

a) La garantía de buen funcionamiento del artículo 932 del Código de Comercio consiste entonces en la obligación convencional que tiene un comerciante frente a otro comerciante de responder por la idoneidad y la calidad del bien, durante un tiempo determinado. Cabe destacar que esta normativa solamente aplica a contratos celebrados entre comerciantes, y no al caso de un contrato celebrado entre un productor (o proveedor) y un consumidor, frente al cual se aplican las normas especiales de protección al consumidor.

Según el artículo 932 del Código de Comercio el término de garantía de buen funcionamiento será el que estipulen las partes y a falta de esta estipulación del término de vigencia de la misma este será de dos años contados a partir del momento de la celebración del contrato. Además, el comprador deberá reclamar al vendedor dentro de los 30 días siguientes al momento en que haya descubierto el defecto. En el caso en que según la costumbre mercantil se venda una mercancía con garantía se aplicará el término acostumbrado en el comercio.

Ahora bien, la diferencia entre la garantía de buen funcionamiento del Código de Comercio y la garantía por calidad e idoneidad de la Ley 1480 de 2011 son las siguientes:

a) La garantía de buen funcionamiento del Código de Comercio aplica solamente en contratos celebrados entre comerciantes, mientras la garantía de calidad e idoneidad del estatuto de protección al consumidor exige la existencia de una relación de consumo, contractual o extracontractual. b) La garantía de buen funcionamiento del Código de Comercio es aplicable solamente si así lo pactan expresamente las partes o si existe costumbre mercantil al respecto. Lo anterior indica que entre comerciantes se puede vender sin garantía, se entenderá así si nada se dice al respecto o en caso de que se estipule expresamente en ese sentido. En cambio, la garantía de calidad e idoneidad del estatuto de protección al consumidor es obligatoria, no se pueden vender $u$ ofrecer bienes nuevos en el mercado sin garantía según la norma.

c) El término de la garantía de buen funcionamiento en materia comercial, cuando esta se pacte, será el que indiquen las partes y en su defecto será de dos años o el que indique la costumbre. Mientras que el término de la garantía del estatuto de protección al consumidor será el que indique el comerciante o en su defecto los términos indicados por la Ley 1480 de 2011. En algunos casos la Superintendencia de Industria y Comercio puede imponer términos obligatorios de garantía, actualmente existen garantías mínimas obligatorias con respecto a vehículos automotores y baterías de vehículos (Circular Única de la Superintendencia de Industria y Comercio). Resulta curioso que el término suplementario incluido por la legislación comercial es más amplio que el que indican las normas de protección al consumidor, lo cual deja dudas sobre el carácter proteccionista de la norma de consumo en este aspecto. Aunque a nuestro modo de ver el consumidor puede optar por el término que más le favorezca en virtud del principio favor consumitoris.

d) La garantía de buen funcionamiento solamente otorga al comprador la facultad de pedir perjuicios y no le concede acción resolutoria o de rebaja del precio (Cárdenas 2007, p. 258). El comprador solamente podrá acudir a esta última cuando se presenten vicios ocultos que hagan la cosa impropia para su natural destinación o para el fin previsto en el contrato. Peña (2010) 
da a entender que se pueden pedir ambas. La garantía de buen funcionamiento del Código de Comercio tiene la naturaleza de una ejecución forzosa de la obligación y por lo tanto no resulta compatible con la acción resolutoria, aunque el comerciante podrá escoger si hace uso de la una o de la otra, según el caso, dejando claro además que esta no es la posición de la Corte Suprema de Justicia.

Asimismo, en concordancia con lo dicho, la Corte Suprema de Justicia en sentencias de septiembre 11 de 2001 y 4 de agosto de 2009 señaló además de la acción de perjuicios el vendedor tiene la obligación de reparar el bien. A su turno la garantía legal en materia de protección al consumidor otorga un plexo de posibilidades que se aplican generalmente en el siguiente orden, reparación, cambio del bien o devolución del dinero. La garantía de protección al consumidor permite acumular perjuicios ante el juez ordinario y no ante la SIC.

e) La garantía de buen funcionamiento se aplica a vicios o defectos intrínsecos de entidad menor, según lo expresado por la Corte Suprema de Justicia colombiana en las referidas sentencias de 2001, 2005 y 2009. Nótese que en la sentencia de 2009, apoyándose en lo dicho en sentencia de 1991, la Corte afirma que si el vicio es mayor procederá la acción derivada del artículo 934 del Código de Comercio, es decir, la llamada acción redhibitoria por vicios ocultos. Mientras la garantía de protección al consumidor se aplica tanto a vicios intrínsecos como aquellos ostensibles, sin importar la gravedad de estos.

En ese orden de ideas quedan sentadas algunas diferencias que permitirán al lector distinguir entre una y otra figura, dejando claro que el tema podría merecer un tratamiento más extenso que excede las pretensiones de este artículo.

\subsection{Diferencias con la responsabilidad por productos defectuosos}

Debido a la imprecisión con que el Decreto 3466 de 1982 trataba el tema de la responsabilidad del productor, es todavía frecuente que en el contexto colombiano no se distinga claramente entre la responsabilidad del productor por garantías y la responsabilidad del productor por productos defectuosos. La responsabilidad del productor por garantías, tal y como quedó indicado, se refiere a la obligación que tienen los productores y proveedores de responder por la calidad e idoneidad de los bienes o servicios que ofrecen en el mercado. En tal sentido se trata de que los bienes y servicios respondan a la calidad ofrecida o esperada de ellos.

A su turno, la responsabilidad del productor por producto defectuoso consiste en la obligación que tienen los miembros de la cadena de valor, específicamente los productores $\mathrm{y} / \mathrm{o}$ proveedores, de responder a los consumidores por los daños ocasionados por los defectos de los bienes o servicios que comercializan. Es decir que esta especie de responsabilidad presupone un daño causado al consumidor o a sus bienes. Mientras que en materia de garantías de trata de garantizar al consumidor que el bien o servicio cuenta con la calidad e idoneidad mínima, la esperada normalmente o la ofrecida, en materia de responsabilidad por productos defectuosos nos encontramos frente a un régimen de responsabilidad especial en el cual se busca indemnizar al consumidor los perjuicios causados por un defecto del bien, el cual puede ser de fabricación, diseño, información o empaque. Acota además la doctrina que el régimen de garantías se refiere a los daños propios del bien o intrínsecos, y la responsabilidad por productos defectuosos corresponde a los daños extrínsecos al bien, comúnmente denominados accidentes de consumo (Stiglitz y Bru, 2009, p. 400).

Barocelli (2012) explica las diferencias conceptuales entre vicio y defecto en materia de 
protección al consumidor: "Muchas veces se ha referido a si los conceptos de "vicio" y "defecto" de la cosa son sinónimos. Sostiene Rinessi, siguiendo el derecho brasileño y comunitario, que la locución "vicio" se debe reservar para los casos en que el producto es impropio para su uso o consumo, se encuentra alterado o, en general, es "inadecuado" para el fin al que está destinado. La cosa tiene ineptitud para el uso o mala calidad. Se trata, en general, de fallas en la cantidad o calidad de los productos, aun cuando no causen daño físico al consumidor. Por contraste, la locución "defecto" se reserva para los casos en que se ocasionan daños fuera del producto mismo, por ejemplo, si tiene su origen en una falta de seguridad esperada" (2012, p. 4) . Siguiendo a este autor el régimen de garantías abarca responsabilidad por "vicios" mientras que el de responsabilidad por productos defectuosos se refiere a los "defectos", aunque como se explica en este artículo la responsabilidad por garantía excede el tema de los vicios.

En síntesis, la Ley 1480 de 2011 diferencia claramente estas dos clases de responsabilidad y les dedica dos títulos aparte lo cual constituye un avance frente al Decreto 3466 de 1982.

\section{CONCLUSIONES}

La responsabilidad del productor por garantía de bienes y servicios en el mercado está regulada en Colombia desde 1982 como un régimen especial de protección al consumidor. No obstante, la Ley 1480 de 2011 amplío la reglamentación de este tema en el ordenamiento jurídico colombiano y a su turno el decreto 0735 de 2013 precisó algunos aspectos de la forma cómo se ejerce y los plazos para el cumplimiento de la misma.

La garantía legal por calidad e idoneidad de bienes y servicios tiene unas características que la individualizan y permiten diferenciarla claramente de otras figuras del derecho privado. Se trata de figuras que conviven y se aplicarán dependiendo de la naturaleza del caso.
La garantía del derecho del consumo cubre aspectos de calidad $e$ idoneidad de bienes y servicios más no de seguridad, este último aspecto se controla a través de otras herramientas legales.

Queda claro que la responsabilidad por garantías del derecho del consumo y la obligación de saneamiento por vicios ocultos presenta diferencias ostensibles y persiguen finalidades diversas.

La garantía de buen funcionamiento del Código de Comercio colombiano y la garantía por calidad e idoneidad igualmente presentan diferencias y un ámbito de aplicación diverso.

La responsabilidad por garantías de bienes y servicios bajo la Ley 1480 de 2011 presenta defectos y virtudes. Como virtudes podemos señalar que se diferenció claramente la responsabilidad por garantía y la responsabilidad por productos defectuosos y además se regularon aparte estas dos especies de responsabilidad de mercado. Igualmente la Ley amplió los conceptos legales sobre la materia, frente a lo cual se evidencia que por primera vez se definió qué es la obligación de garantía y se redefinieron los conceptos de calidad e idoneidad. Además se estipularon términos claros de garantía legal, aspecto que tenía un claro vacío en el Decreto 3466 de 1982.

Como defectos se evidencia que los términos mínimos de garantía son subsidiarios y no obligatorios, lo cual demuestra tibieza a la hora de legislar para proteger al consumidor. Igualmente se puede criticar la admisión de la fuerza mayor y el hecho de un tercero como causales de exoneración de responsabilidad del productor por garantía de bienes y servicios, que desnaturaliza la obligación de garantía. Además, el hecho de que la Superintendencia de Industria y Comercio no cuente con la facultad de ordenar indemnización de perjuicios en materia de garantías, limita su margen de maniobra como juez. Igualmente ha sido criticada la aplicación del régimen de garantías 
en materia de servicios de profesionales que tienen a cargo obligaciones de medio.

\section{REFERENCIAS}

Barocelli, S. S. (2012). El régimen de garantías en el sistema de defensa del consumidor. Revista Doctrina Judicial, 1-10.

Bonivento, J. A. (2012). Los principales contratos civiles y su paralelo con los comerciales. Bogotá: Librería Ediciones del Profesional.

Cárdenas, J. P. (2007). La resolución por problemas de funcionamiento de la cosa en el derecho colombiano. En Gaitán, J. A. \& Mantilla, F. (dir.). La Terminación del Contrato. Bogotá: Universidad del Rosario.

De la Cruz, D. M. (2012). La garantía legal y la responsabilidad por producto defectuoso en el nuevo Estatuto del Consumidor. Con-texto. Revista de Derecho y Economía, 37, 11-35.

Farina, J. M. (2009). Derechos de los Consumidores y Usuarios. Buenos Aires: Astrea.

Fernández, M. (2013). La transposición del modelo del consumo al campo médico sanitario, reflexión sobre sus efectos a nivel de responsabilidad. En Gual, J. M. y Villalba, C. (dir.) Derecho del consumo. Problemáticas actuales. Bogotá: Ibañez.

Giraldo, A., Madriñan R. \& Caycedo C. (2012). Comentarios al Nuevo Estatuto del Consumidor. Bogotá: Legis.

Gómez, C. (2008). De los principales contratos civiles. Bogotá: Editorial Temis.

Hise, M. (2011). Los vicios redhibitorios y las garantías legales. Ghersi, C. \& Weingarten, C. (Directores). Manual de los derechos de los consumidores y usuarios. Buenos Aires: Editorial La Ley.

Lorenzetti, R. L. (2004). Tratado de los Contratos. Buenos Aires: Rubinzal Culzoni Editores.

Mantilla, F. (2013). La garantía de buen funcionamiento de la cosa vendida en el Código de Comercio Colombiano. Revista Foro de Derecho Mercantil, 93-118.

Mosset, J. \& Wajntraub, J. (2008). Ley de Defensa del Consumidor. Buenos Aires: Rubinzal Culzoni Editores.

Oviedo, J. (2010). Sobre el concepto de vicio redhibitorio en la compraventa. Análisis comparado de la jurisprudencia chilena y colombiana. Revista Chilena de Derecho. 37, 2. 241- 269 .

Peña, L. (2010). Contratos Mercantiles, nacionales e internacionales. Temis: Bogotá.

Rinessi, A. J. (2006). Relación de consumo $y$ derechos del consumidor. Buenos Aires: Astrea.

Rusconi, D. (Coord.). (2009). Manual de Derecho del Consumidor. Buenos Aires: Abeledo Perrot.

Tamayo, A. (2004). El Contrato de Compraventa, su régimen civil y comercial. Bogotá: Ediciones Doctrina y Ley.

Tamayo, J. (2012, marzo 12). La responsabilidad civil en el nuevo Estatuto del Consumidor. Ámbito Jurídico, 12.

Villalba, J. C. (2012). Introducción al Derecho del Consumo. Bogotá: Universidad Militar Nueva Granada.

Zentner, D. H. (2010). Contrato de Consumo. Buenos Aires: Editorial La Ley. 